\title{
Making Hospital Governance Healthier for Nurses
}

\author{
K Clark and S Beatty
}

\begin{abstract}
The current research examined front line nurse expectations of non-metropolitan public hospital governance. In doing so, it explored the relevance of two dominant, competing Agency and Stewardship governance theories to these organisations.
\end{abstract}

Two studies were conducted with the first establishing an inventory of notional nurse preferences for governance and the second testing these with a random sample of front-line non-metropolitan hospital nurses across one Australian State, with the aim of identifying valid and reliable measures.

The study data suggest nurses working in nonmetropolitan public hospitals expect governance practices to reflect: respect for and engagement with clinical perspectives; utilisation of evidence- based planning; and effective engagement with local communities. Scales with good consistency and criterion and construct validity measuring these three components were identified.

The study provides evidence that nurses expect and value a style of hospital governance that is consistent with Stewardship Theory. The results also suggest that governance is an important enough issue for nurses that it significantly affects their turnover intentions. This has important implications for healthcare leaders concerned about the sustainability of public hospitals.

Abbreviations: NPM - New Public Management; PCA - Principal Components Analysis.

Key words: nurses; managers; hospitals; governance.

\section{Kim Clark}

Edith Cowan - University Ringgold Standard Institution School of Medical \& Health Sciences

Western Australia, Australia.

\section{Shelley Beatty}

Edith Cowan - University Ringgold Standard Institution School of Medical \& Health Sciences

Western Australia, Australia.

\section{Correspondence:}

s.beatty@ecu.edu.au

\section{Introduction}

Public hospitals account for the majority of acute-care provision in Australia and consequently play a critical role in the nation's health system. [1] Issues that affect the satisfaction and retention of clinical staff in public hospitals are therefore matters of considerable concern.

The Australian Productivity Commission [2] identified high levels of early-career departure from the health professions, pointing to hospital environments as an important area for research into clinician satisfaction and retention. In these settings, relationships between managers and clinicians are critical, because as Blaauw, Gilson, PennKekana, and Schneider [3] argue, they are the vehicle by which organisational outcomes are realised in healthcare. Foundational influences on manager-staff relationships are located in the domain of governance. Fukuyama [4] interpreted good governance as requiring appropriate levels of agent (i.e. staff) autonomy for decision-making to be ascertained. To do this, managers need to make accurate judgments about their staff's motivations vis-à-vis their work. As Fukuyama indicates, this is not always easy and what is appropriate in one setting could be counterproductive in another.

Two theories have come to dominate the question of the appropriate levels of agent autonomy. [5] Stewardship Theory makes room for higher levels of autonomy, because it posits in agents the potential to share common interests and to have the desire to cooperate with their principals (i.e. managers). [6] In doing so, this theory fits with Fukuyama's view that governance needs to be tailored to its context. [4] The alternative and more influential Agency Theory assumes governance always entails conflicting interests among principals and agents [6] and suggests there needs to be 
a focus on controlling the propensity of agents to behave according to self-interest.

Notwithstanding Fukuyama's [4] contention of the need to match governance to settings, recent decades of public sector reform both in Australia and elsewhere have been singularly underpinned by New Public Management (NPM). NPM has situated Agency Theory as a cornerstone influence on public sector governance. Reflecting its reach into public hospitals, Degeling and Carr characterised pre-2000 Australian health reforms as occurring with 'little examination of the attitudes, values and beliefs of those subject to the reform process' [7 p. 403]. Subsequently Newman and Lawler [8] referred to the dominance of governance oriented to measuring clinical output and to controlling clinicians' performance.

Empirical data on the general veracity of such claims has been a gap in Australian health sector research. There is some historical data from the 1990s relating to the initial influence of NPM. Drawing on studies that involved almost 30,000 Australian employees in roughly 3,000 public and private sector workplaces [9] this provides empirical support for claims of declining concern with front-line perspectives in the public-sector in the early period of NPM. These data don't, however, shed light on whether the change had been beneficial to public sector performance nor do they address whether the change had negatively affected staff. Fukuyama's assessment suggests the answers to these questions would be 'it depends on the setting.' [4]

Reflecting the triple themes of: (a) a need for contextspecific governance data; (b) concerns about high levels of early-career departure from the health professions; and (c) the importance of hospital environments as foci for research into clinician satisfaction and retention, the current study investigated nurses' perspectives of governance in a number of Australian non-metropolitan public hospitals.

The centre-piece of the study was the modest but important goal of identifying signs of the appropriate theoretical alignment of hospital governance insofar as nurses were concerned (i.e. Agency or Stewardship Theory) and assessing whether this seemed likely to make a difference to hospital functioning. To do this, two studies were undertaken culminating in the construction of nurse governance preference scales and assessing these against an existing scale that measured nurses' turnover intentions.

The approach taken followed standard conventions of scale development, complementing use of literature, and qualitative research to generate items followed by a survey. [10] The governance scales developed were interpreted as reflecting nurses' psychological constructions of governance preferences. [11] The analytical approach taken accorded with literature on the development of instruments with this focus. [12]

While nurse work motivations have been little researched [13] there are reasons to suspect it might resonate with the assumptions underpinning Stewardship Theory. These afford agents the potential to have higher-order concerns than self-interest, to be pro-organisational, and trustworthy. [14-16]

At first glance, there might be a temptation to consider clinicians' expectations of governance a second-order priority in hospital settings. An alternative interpretation, however, deserves consideration. In particular, it seems likely that the combination of professional training in healthcare and the character of hospital work instil clear expectations of good governance amongst hospital-based clinicians like nurses. [17] Violation of these seems likely to affect job attitudes and behaviours, [18] to be detrimental to organisational commitment and to lead to disinterest in anything beyond directly serving patients' interests. For these reasons, research into clinicians' expectations of governance is directly relevant to the critical issues of public hospital efficiency and effectiveness, which underpin sustainability.

\section{Methods and results}

This research comprised two studies both of which had ethics approval from the research ethics committee of Edith Cowan University (08-35 CLARK). The first study was a series of in-depth interviews with highly experienced senior public health managers. From these interviews, an inventory of 110 governance practices was constructed in the form of Likert scale items. This inventory was tested in a second study that was a cross sectional random sample survey of nursing staff working in non-metropolitan public hospitals across one Australian State. These included hospitals in large regional centres, mid-sized towns and smaller rural loccations. The following sections outline the methods and results from the two studies.

\section{Method Study 1: Interviews with managers}

Nineteen senior clinician-managers working in one State government health department and one former senior healthcare manager were approached to assess their willingness to participate in key informant interviews on governance in public hospitals. These 'expert opinion' interviews were used to establish preliminary or 'in-principle' clarification of the theoretical alignment of the governance 
preferences of hospital nurses. Further to this, they were used to identify governance practices 'experts' believed frontline hospital nurses valued or expected.

Sixteen of the managers approached agreed to be interviewed and were available during the study period. Prior to interview, each was given a detailed outline of the nature of questions they would be asked (e.g. 'I'd like you to reflect on your views of the characteristics of effective non-metropolitan public hospitals. What attributes and practices would characterise the organisation's relationships with clinicians?'). Interviewees were assured of anonymity and each gave written consent to participate. Interviews were undertaken on a one-to-one basis using a structured open-ended questionnaire supplemented with probing to elucidate deeper reflections.

Most interviews were conducted by phone, with a small number undertaken face-to-face, and most were of approximately one hour's duration. Extensive notes were taken during interviews and these were subsequently used to extract themes and to build an inventory of governancerelated behaviours or practices that respondents regarded as being associated with management effectiveness in nonmetropolitan public hospitals.

Fifteen respondents were clinician managers, with ten having a background in nursing and five being medically trained. The remaining respondent was a former senior manager with extensive experience with a national healthcare management organisation and in hospital accreditation. Thus, all interviewees had extensive experience working with nurses in hospitals, with most having more than 25 years' health system experience along with clinical training, which was predominantly in nursing.

\section{Results: Study 1}

Interview data suggested respondents believed that hospital nurses expected governance based on a perception of shared employee-organisation commitment to a common aim and an agreement on mutual notions of fair treatment. The overwhelming perspective offered by interviewees aligned with Stewardship Theory. Interview data also resonated with Caldwell and Karri's [18] proposition that employer violation of nurses' governance expectations negatively affected their job attitudes. The effects suggested included lower levels of organisational commitment and a lack of interest in organisational imperatives beyond serving patients' interests. Interviewees generally contended that hospital governance should emphasise shared clinician-organisation responsibility for patient and population health.

A further issue that emerged from interviews was the proposition that nurses distinguished and often held different attitudes about governance pertaining to the different levels of the public health system (i.e. institutional, organisational, and work level). Local organisational or 'work-level' governance was regarded as more important to nurses than the other levels.

Interviewee perspectives on work-level governance aligned with Clark and Payne's [19] characterisation of the categories or areas that influence whether staff trust their managers. These perspectives were:

- Integrity (i.e. sincerity, honesty, promise fulfilment);

- Competence (i.e. technical and interpersonal knowledge and skills);

- Consistent behaviour (i.e. fairness, predictability, good judgement);

- Loyalty or benevolent motives (i.e. based on shared values and goals, commitment to staff etc.); and

- Openness or mental accessibility or availability (i.e. willingness to share ideas and information).

\section{Methods Study 2: Survey of Nurses}

Study 2 drew on Study 1 data, entailing compilation of an 'expert-identified' inventory of nurse governance preferences. This was converted into a questionnaire format and tested and refined via a sample survey of public hospital nurses. The questionnaire included a section oriented to governance at the hospital level (79 items) and a section on broader or overall organisational governance. Local hospital items are the focus of the remainder of this paper.

A final section of the questionnaire comprised a 14-item 'intention to stay' scale (i.e. measuring nurse turnover expectations). This was included for use in validating governance measures. Intention to stay was measured using a validated scale previously used in a study of the turnover intentions of South African hospital nurses. [20] Approval to use the scale was obtained from its author. A fourth section of the questionnaire included items of a demographic, work history and professional training nature.

As a preliminary check on design and item validity, a draft version of the questionnaire was sent to people interviewed in Study 1 and to academic colleagues. An accompanying request sought feedback on the appropriateness of items (wording etc), use of scales and on possible gaps in coverage. Suggested amendments were incorporated into the final draft of the questionnaire used in Study 2.

To facilitate Study 2, the employer public health organisation drew a simple random sample of 200 names and addresses of front-line hospital nurses from its employee database. One duplicate was subsequently found in the sample meaning the number of eligible nurses was 199. An outline 
of the study and an invitation to participate in the study was mailed to these nurses. The letter advised that in light of anonymity of responses, completion and return of the questionnaire would be taken as consent.

One follow-up reminder was sent to all recipients two weeks after the initial mail-out. After removing four non-contacts relating to post office notification of relocation or returns marked 'on overseas travel', the response fraction was 86/195 (i.e. 44\%). This exceeded levels achieved in most surveys [21] and met Jackson and Furnham's [22] minimum level for survey acceptability (i.e. 35\%).

Data were entered and analysed using a personal computer version of SPSS (SPSS15.0 for Windows). The analysis explored underlying patterns within responses and item performance. It also examined the correlation between responses and turnover intentions.

To explore patterns in responses to governance items, Principal Components Analyses (PCAs) were undertaken using Varimax (orthogonal) rotation. Tabachnick and Fiddell [23] recommended this approach as the appropriate first step in analysing data where the goal was reduction of items and exploration of probable factors. PCA component matrices were then assessed to examine individual item results and factor interpretability. An iterative cycle of removing ambiguous items (i.e. they had high loadings on more than one factor) and rerunning the PCA was followed until all remaining items loaded on only one factor and all the factors were readily interpretable. The analytic process accorded with that recommended by Tabachnick and Fidell [23] and Field. [24]

\section{Results: Study 2}

Age and gender bias in response was checked using twotailed Chi-square tests and in both cases, the results were not significant ( $p>$.05). The result of the PCA was that in relation to the hospital level governance, a three-component solution was considered the most interpretable (see Table 1).

Broadly, these three components related to the issues of:

1. Respect and support for, and engagement with, clinical staff;

2. Use of evidence to make decisions and to plan developments for the service; and

3. Understanding of, and links to, the local community.

Reliability analysis was undertaken for items comprising each of the three components (i.e. they were treated as scales) with the resultant Cronbach's alpha scores $(1=0.966$, $2=0.940,3=0.925$ ) indicating good consistency and reliability.

Subsequently, bivariate correlation coefficients between the three scales and the Turnover Intentions Scale were calculated and two-tailed tests of significance were performed. The results of these analyses are detailed in Table 2. The low-moderate correlations (i.e. $-0.462,-0.561$, -0.571) provide evidence of the relevance of work-level

Table 1: Eigenvalues and Rotated Loadings

\begin{tabular}{|l|c|c|c|c|}
\hline & \multicolumn{2}{|c|}{ INITIAL EIGENVALUES } & \multicolumn{2}{c|}{ ROTATED SUMS OF SQUARED LOADINGS } \\
\hline & TOTAL & \% OF VARIANCE & TOTAL & \% OF VARIANCE \\
\hline Component 1 & 42.0 & 54.5 & 21.8 & 28.3 \\
\hline Component 2 & 2.8 & 3.7 & 16.9 & 11.1 \\
\hline Component 3 & 2.4 & 3.1 & 8.6 & 61.3 \\
\hline Total & & & & \\
\hline
\end{tabular}

Table 2: Correlations - Local Hospital Governance Scales and Turnover Intention Scale

\begin{tabular}{|l|c|c|}
\hline SCALES & PEARSON CORRELATION & SIGNIFICANCE (2 - TAILED) \\
\hline $\begin{array}{l}\text { Respect and support for, and engagement with, clinical staff } \\
\text { (related to Trust in Management) }\end{array}$ & -0.571 & $\mathrm{p}<0.01$ \\
\hline $\begin{array}{l}\text { Use of evidence to make decisions and to plan developments } \\
\text { for the service (related to Stewardship Governance) }\end{array}$ & -0.561 & $\mathrm{p}<0.01$ \\
\hline $\begin{array}{l}\text { Understanding of, and links to, the local community (related } \\
\text { to Stewardship Governance) }\end{array}$ & -0.462 & $\mathrm{p}<0.01$ \\
\hline
\end{tabular}


governance to the sustainability and effective functioning of these organisations.

\section{Discussion}

This research explored effective governance in Australian public hospitals. Nurses'expectations of hospital governance were characterised in an inventory of items which were then evaluated and refined into reliable and valid scales pertaining to dimensions of nurses' governance preferences. These were then used to investigate the relevance of nurses' governance preferences to their turnover intentions.

While the scope of the two studies reported in this paper was limited, the results point to the governance in hospitals being sufficiently important to affect nurses' intentions regarding tenure. This is important if only because nursing shortages are evident in Australia's public health system and there is high level early-career departure from the profession. [25-27] More substantially, however, any decision about quitting seems likely to be preceded on myriad adverse organisational impacts of clinician dissatisfaction on the running of hospitals.

The findings from the two studies suggest nurses working in public hospitals expect and value a specific style of governance. This seems a style that accords with Bolton's [28] assessment of nurses having the motivation to achieve the best for patients and as having a keen interest in the processes they envisage will produce these outcomes. It seems reasonable to expect that this motivation will be found among other groups of clinicians working in public hospitals.

Thus, a governance imperative in public hospitals might relate less to managing the risk of clinicians pursuing selfinterest as Agency Theory suggests and more to proactively responding to their desire that these organisations respond to the best interests of patients; ensure evidence drives decisions; and establishing a clear agenda for improving services. This conception of governance resonates with the tenets of Stewardship Theory, suggesting leaders of Australia's rural public hospitals should actively attend to its premises.

Notably, the findings of the current studies do strike a chord with the findings of Morrell, Loan-Clarke, Arnold, and Wilkinson [29] from their study of the causes of voluntary nurse turnover in the United Kingdom National Health Service. Similar to the findings of the current study, Morrell et al suggested nurses' schema of organisational governance practices played an important role in their evaluations of their workplace and that when nurses experienced perceived violations of professional and personal values and ethics, they were more inclined to leave their jobs.

While the current research is a preliminary contribution and needs to be replicated in differing contexts such as urban and other jurisdictions, it does highlight important areas for further research and development in the field of hospital governance.

\section{Acknowledgements}

The authors extend their thanks to all the research participants, especially to the front-line hospital nurses who contributed their time to this study.

\section{Competing interests}

The authors declare that they have no competing interests.

\section{References}

1. Australian Institute of Health and Welfare (AlHW). Australia's health 2014. Canberra: AlHW; 2014.

2. Productivity Commission. Australia's health workforce: Research Report. Melbourne: Productivity Commission; 2005.

3. Blaauw D, Gilson L, Penn-Kekana L, Schneider H. Organisational relationships and the 'software'of health sector reform. Witwatersrand, South Africa: Centre for Health Policy School of Public Health: University of Witwatersrand; 2003.

4. Fukuyama F. What is governance? Governance. 2013;26:347-368.

5. Van Puyvelde S, Caers R, Du Bois C, Jegers M. The governance of nonprofit organizations integrating agency theory with stakeholder and stewardship theories. Nonprofit and Voluntary Sector Quarterly. 2012;41:431-451.

6. Caers R, Bois CD, Jegers M, Gieter Sd, Schepers C, Pepermans R. Principal-agent relationships on the stewardship-agency axis. Nonprofit Management and Leadership. 2006;17:25-47.

7. Degeling P, Carr A. Leadership for the systemization of healthcare: the unaddressed issue in healthcare reform. J Health Organ Manag. 2004;18:399-414.

8. Newman S, Lawler J. Managing healthcare under New Public Management: a Sisyphean challenge for nursing. Journal of Sociology. 2009;45:419-432.

9. O'Donnell M, Allan, C, Peetz, D. The new public management and workplace change in Australia. Working Paper No. 126. Sydney: School of Industrial Relations and Organisational Behaviour, University of New South Wales; 1999.

10. Turker D. Measuring corporate social responsibility: a scale development study. Journal of Business Ethics. 2009;85(4):411-27.

11. Ford JK, MacCallum RC, Tait M. The application of exploratory factor analysis in applied psychology: a critical review and analysis. Pers Psychol. 1986;39(2):291-314.10.

12. Floyd FJ, Widaman KF. Factor analysis in the development and refinement of clinical assessment instruments. Psychol Assess. 1995;7(3):286.11.

13. Toode K, Routasalo P, Suominen T. Work motivation of nurses: a literature review. Int J Nurs Stud. 2011;48:246-257.

14. Armstrong JL. Stewardship and public service: a discussion paper. In: Commission. CPS, editor. Ottawa, Canada: Canadian Public Service Commission; 1997.

15. Davis JH, Schoorman FD, Donaldson L. Toward a stewardship theory of management. Acad Manag Rev. 1997;22:20-47. 
16. Saltman RB, Ferroussier-Davis O. The concept of stewardship in health policy. Bulletin of the World Health Organization. 2000; 78:732-739.

17. Shapiro SP. Agency theory. Annual Review of Sociology. 2005: 31:263-284.

18. Caldwell C, Karri R. Organizational governance and ethical systems: a covenantal approach to building trust. Journal of Business Ethics. 2005;58:249-259.

19. Clark MC, Payne RL. The nature and structure of workers' trust in management. Journal of Organizational Behavior. 1997;18:205-224.

20. Jacobs E, Roodt G. Organisational culture of hospitals to predict turnover intentions of professional nurses. Health SA, Gesonheid. 2008;13:63-78.

21. Maylor H, Blackmon K. Researching business and management: a roadmap for success. New York: Palgrave Macmillan; 2005.

22. Jackson CJ, Furnham A. Designing and analysing questionaires and surveys: a manual for health professionals and administrators. Hoboken, NJ: Wiley; 2000.

23. Tabachnick BG, Fidell L. Using multivariate statistics. Boston Massachusetts: Allyn and Bacon; 2001.

24. Field A. Discovering statistics using SPSS. London: Sage Publications; 2009.

25. Francis K. Health and health practice in rural Australia: where are we, where to from here? Online Journal of Rural Nursing and Healthcare. 2012;5:28-36.

26. Bennett P, Barlow V, Brown J, Jones D. What do graduate registered nurses want from jobs in rural/remote Australian communities? J Nurs Manag. 2012;20:485-490.

27. Duffield C, Roche M, O'Brien-Pallas L, Catling-Paull C, King M. Staff satisfaction and retention and the role of the nursing unit manager. Collegian. 2009;16:11-17.

28. Bolton SC. A simple matter of control? NHS Hospital Nurses and New Management Journal of Management Studies. 2004; 41:317-333.

29. Morrell K, Loan-Clarke J, Arnold J, Wilkinson A. Mapping the decision to quit: a refinement and test of the unfolding model of voluntary turnover. Applied Psychology. 2008;57:128-150. 